\title{
SISTEM INFORMASI AKADEMIK SEKOLAH BERBASIS WEBSITE (Studi Kasus: SMK 11 Maret Jakarta)
}

\author{
Dicky Hariyanto ${ }^{1}$, Tania Meidiany ${ }^{2}$ \\ ${ }^{1}$ AMIK BSI Bogor \\ Jl. Merdeka No, 168 Bogor Tengah - Kota Bogor \\ e-mail: dicky.dkh@bsi.ac.id \\ ${ }^{2}$ AMIK BSI Bogor \\ JI. Merdeka No, 168 Bogor Tengah - Kota Bogor \\ e-mail: taniameidiany18@gmail.com2
}

\begin{abstract}
Abstrak
Seiring dengan perkembangan ilmu pengetahuan dan teknologi saat ini, dimana kita tidak lagi dibatasi waktu dan tempat. Manusia semakin dimudahkan dalam memperoleh suatu informasi. Kebutuhan manusia akan informasi pada saat ini menjadi begitu mudah terpenuhi dengan adanya internet, yang memungkinkan kita melakukan transfer informasi hanya dalam hitungan menit. Waktu dan ruang tidak menjadi persoalan bagi mereka yang jauh dari sumber informasi. Pada sekolah SMK 11 Maret Jakarta selama ini sistem informasi tentang sekolah masih disampaikan secara langsung kepada siswa maupun guru atau menggunakan media ketas sebagai penyampaian informasi sekolah. Begitu juga dengan nilai siswa masih disampaikan secara langsung kepada siswa atau orang tua siswa. Dan pada pemberian tugas kepada siswa masih diberikan secara langsung oleh guru ketika mengajar dikelas. Dengan begitu penulis menyelesaikan Tugas Akhir dengan membuat Perancangan Sistem Informasi Akademik Sekolah Berbasis Web Pada Sekolah SMK 11 Maret Jakarta dengan menggunakan Adobe dreamwaever. Sistem Informasi Akademik ini akan memudahkan bagi pihak sekolah dalam membantu guru untuk memberitahukan tentang nilai siswa dan memberikan tugas kepada siswa dengan mudah, dan siswa pun dapat dengan mudah melihat nilainya melalui web.
\end{abstract}

Kata Kunci: Sekolah, SISFO, Web

\begin{abstract}
Along with the development of science and technology today, where we are no longer limited time and place. Humans are increasingly facilitated in obtaining information. The human need for information at this time becomes so easily fulfilled with the internet, which allows us to transfer information in just minutes. Time and space do not matter to those who are away from information sources. In the vocational school 11 March Jakarta during this information system about the school is still delivered directly to students or teachers or use the media as a delivery of ketas school information. So also with the value of students are still delivered directly to students or parents of students. And on assignment to students is still given directly by the teacher when teaching in class. Thus the authors completed the Final Project by making the Design of Academic Information Systems Web-Based School at SMK 11 March Jakarta by using Adobe DreamWeaver. This Academic Information System will make it easier for the school in helping teachers to tell students about grades and assign tasks to students easily, and students can easily see their value through the web.
\end{abstract}

Keywords: School, SISFO, Web 


\section{Pendahuluan}

Pendidikan merupakan hal yang sangat penting, karena dengan pendidikan suatu negara akan maju. Hal yang terpenting untuk memajukan suatu negara adalah adanya penerus bangsa yang berkualitas, serta tenaga kerja yang siap pakai. Untuk itu diperlukan adanya sekolah yang bermutu agar dapat berperan membantu pemerintah dalam mendapatkan sumber daya manusia yang siap pakai, maka SMK 11 Maret Jakarta dapat melahirkan sumber daya sebagai generasi bangsa yang siap pakai untuk membangun bangsa dan negara Indonesia agar lebih maju.

Seiring dengan perkembangan ilmu pengetahuan dan teknologi saat ini, dimana kita tidak lagi dibatasi waktu dan tempat. Manusia semakin dimudahkan dalam memperoleh suatu informasi. Kebutuhan manusia akan informasi pada saat ini menjadi begitu mudah terpenuhi dengan adanya internet, yang memungkinkan kita melakukan transfer informasi hanya dalam hitungan menit. Waktu dan ruang tidak menjadi persoalan bagi mereka yang jauh dari sumber informasi.Penerapan teknologi e-commerce merupakan salah satu faktor yang penting untuk menunjang keberhasilan suatu produk dari sebuah perusahaan, untuk mempercepat dan meningkatkan penjualan cepat, dengan memanfaatkan suatu layanan secara online yang berupa e-commerce (Sunarto, A., 2009).

Pada sekolah SMK 11 Maret Jakarta selama ini sistem informasi tentang sekolah masih disampaikan secara langsung kepada siswa maupun guru atau menggunakan media kertas sebagai penyampaian informasi sekolah. Begitu juga dengan nilai siswa masih disampaikan secara langsung kepada siswa atau orang tua siswa. Sama halnya pada pemberian tugas kepada siswa masih diberikan secara langsung oleh guru ketika mengajar dikelas.

\section{Metode Penelitian}

Metode pengumpulan data "Model SDLC air terjun (waterfall) sering juga disebut sekuensial linier (sequential linier) atau alur hidup klasik (classic life cycle)" (Rosa dan M. Shalahuddin, 2013).
Model air terjun menyediakan pendekatan alur hidup perangkat lunak secara sekeuensial atau terurut dimulai dari analisis, desain, pengodean, pengujian, dan tahap pendukung (support). Model waterfall dapat dilihat pada gambar di bawah ini:

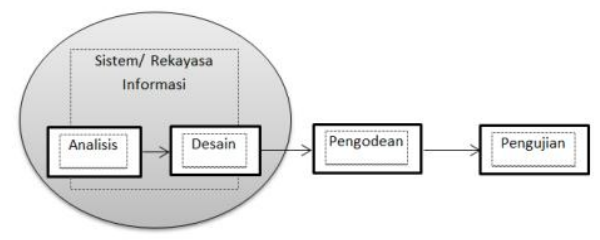

Sumber: Rosa dan Salahuddin (2013)

Gambar 1. Model Waterfall

1. Analisis kebutuhan perangkat lunak Proses pengumpulan kebutuhan dilakukan secara intensif untuk mespesifikasi kebutuhan perangkat lunak agar dapat dipahami perangkat lunak seperti apa yang dibutuhkan oleh user. Spesifikasi kebutuhan perangkat lunak pada tahap ini perlu di dokumentasikan.

2. Desain

Desain perangkat lunak adalah proses multi langkah yang fokus pada desain pembuatan program perangkat lunak termasuk struktur data, artsitektur perangkat lunak, representasi antarmuka, dan prosedur pengkodean. Tahap ini mentranslasi desai agar dapat diimplementasikan menjadi program pada tahap selanjutnya. Desain program perangkat lunak yang dihasilkan, pada tahap ini juga perlu didokumentasikan.

\section{Pembuatan Kode Program}

Desain harus ditranslasikan kedalam program perangkat lunak. Hasil dari tahap ini adalah program komputer sesuai desain yang telah dibuat pada tahap desain. Program yang digunakan yaitu Adobe Dreamwaever.

4. Pengujian

Pengujian fokus pada perangkat lunak secara dari segi lojik dan memastikan bahwa semua bagian sudah diuji. Hal ini yang dilakukan untuk menimalisir kesalahan (error) dan memastikan keluaran yang 
dihasilkan sesuai dengan yang diinginkan.

5. Pendukung (support) atau Pemeliharaan (maintenance)

Tidak memungkinkan sebuah perangkat lunak mengalami perubahan ketika sudah dikirimkan ke user. Perubahan biasa terjadi karena adanya kesalahan yang muncul dan tidak terdeteksi saat pengujian atau peragkat lunak harus beradaptasi dengan lingkungan yang baru. Tahap pendukung atau pemeliharaan dapat mengulangi proses pengembangan mulai dari analisis spesifikasi untuk perubahan perangkat lunak yang sudah ada, tapi tidak untuk membuat perangkat lunak baru.

\section{Hasil dan Pembahasan}

\subsection{Analisis Kebutuhan Pengguna}

Menganalisa kebutuhan siapa saja yang dapat menggunakan sistem informasi ini berguna untuk mengelompokkan fungsi dan fasilitas yang bisa digunakan dari masingmasing pengguna. Terdapat 3 jenis pengguna yang bisa mengakses dan memanfaatkan fasilitas yang terdapat pada website sistem informasi akademik, sebagai berikut:

A. Admin

1. Dapat login ke dalam halaman khusus administrator

2. Menambah, mengubah, menghapus data admin, guru, siswa, kelas, matapelajaran, jadwal mengajar, artikel

B. Guru

1. Dapat login ke dalam halaman khusus Guru

2. Melihat jadwal mengajar

3. Memasukkan data nilai siswa

4. Mengunggah soal untuk tugas siswa

5. Mengunduh jawaban tugas siswa

C. Siswa

1. Dapat login ke dalam halaman khusus Siswa

2. Melihat \& mencetak nilai
3. Mengunduh soal tugas dari guru

4. Mengunggah jawaban tugas

5. Melihat informasi sekolah

\subsection{Perancangan Perangkat Lunak}

Merupakan penjelasan rinci yang berkaitan dengan tampilan antar muka seluruh program, basis data, struktur navigasi, implementasi sebagai berikut:

A. Rancangan Antar Muka

1. Rancangan antar muka index / menu utama

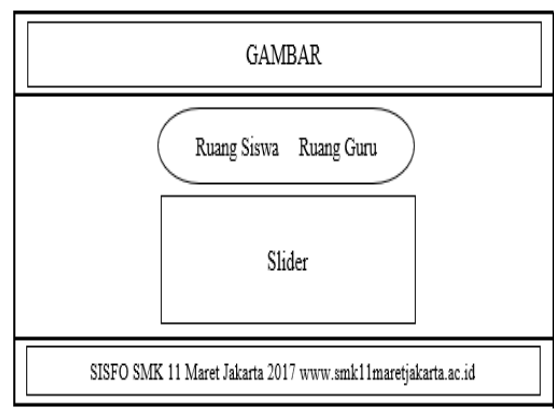

Sumber: Hasil Penelitian (2017)

Gambar 2. Antar Muka Index

2. Rancangan antar login admin

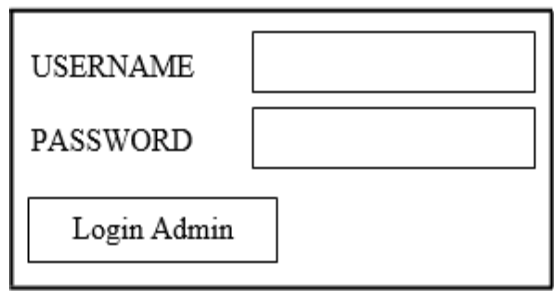

Sumber: Hasil Penelitian (2017)

Gambar 4. Antar Muka Login Admin

3. Rancangan antar muka home admin

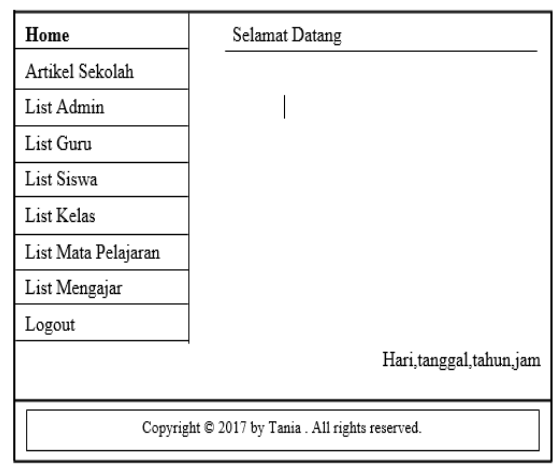

Sumber: Hasil Penelitian (2017)

Gambar 4. Antar Muka Home Admin 


\section{B. Rancangan Basis Data}

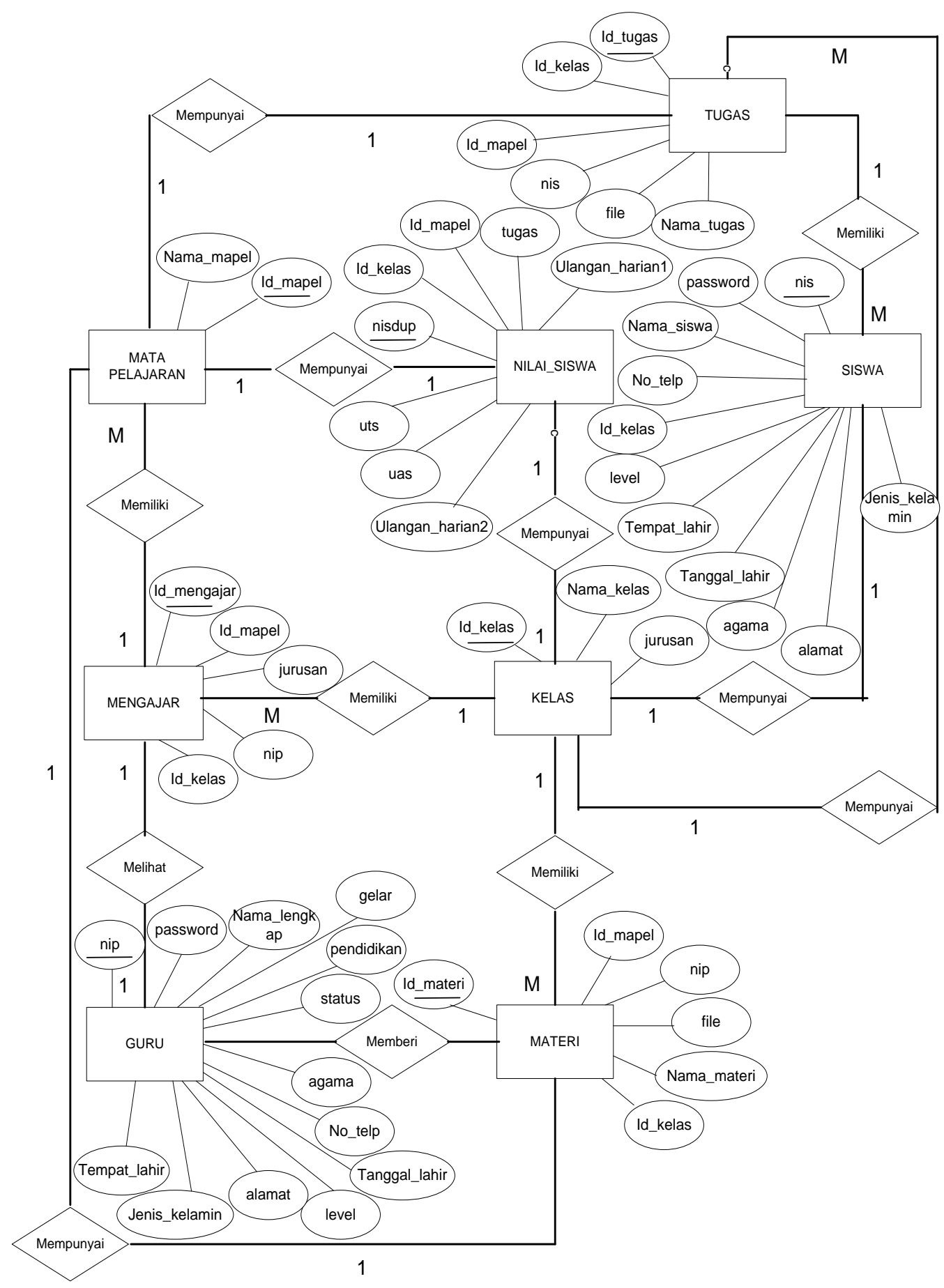




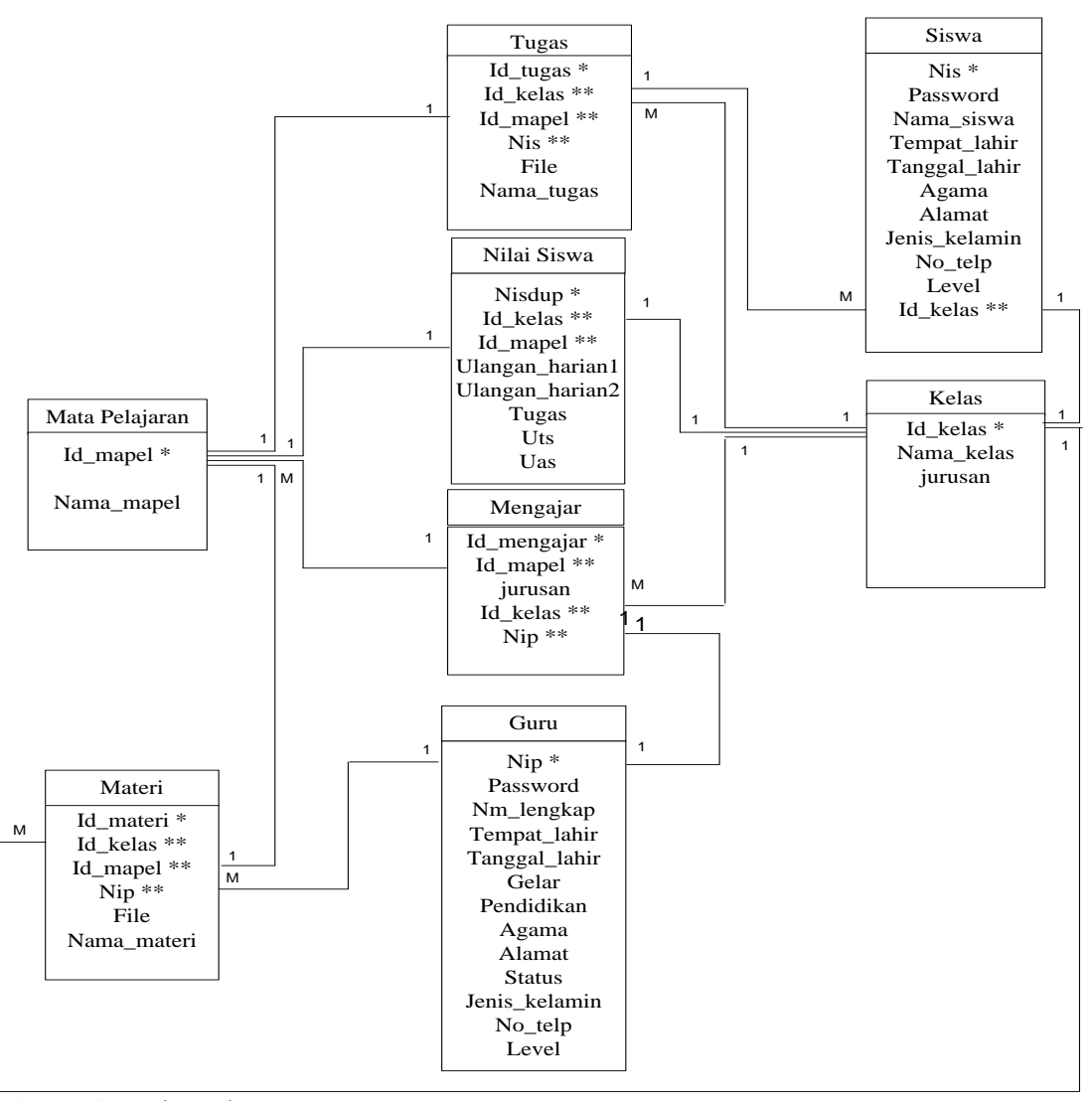

Sumber: Hasil penelitian (2017)

Gambar 6. Logical Record Structure

C. Implementasi

1. Halaman antar muka index / menu utama

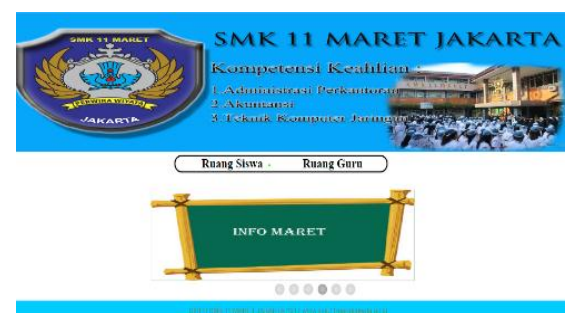

Sumber: Hasil Penelitian (2017)

Gambar 7. Halaman Antar Muka Index

3. Halaman antar muka home admin
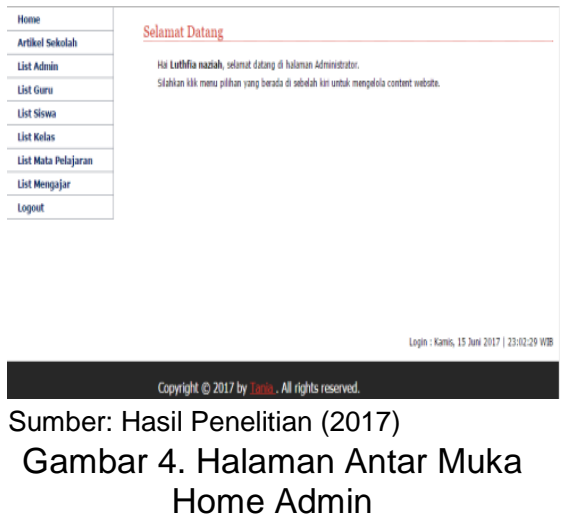

2. Halaman antar login admin

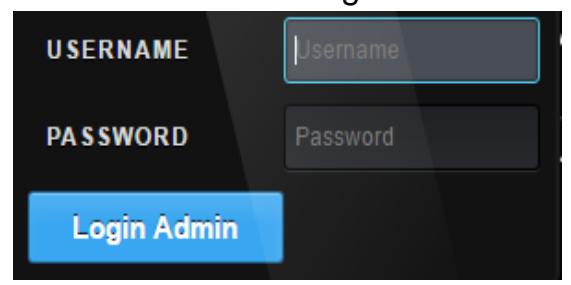

Sumber: Hasil Penelitian (2017)

Gambar 8. Halaman Antar Muka Login Admin

\section{Kesimpulan}

Berdasarkan pembahasan pada babbab sebelumnya, penulis menarik kesimpulan mengenai Sistem Informasi Akademik pada SMK 11 Maret Jakarta diantaranya, Sistem Informasi Akademik sekolah diharapkan mampu untuk memberikan kemudahan bagi penggunanya dan dapat membantu dan mempermudah dalam menyampaikan informasi kepada guru dan siswa. Selain 
itu, dengan menggunakan website sekolah ini guru dapat memberikan tugas untuk siswa dan memberikan nilai langsung melalui website.

\section{Referensi}

Abdulloh, Rohi. 2015 . Web Programing is Easy. Jakarta: PT. Elex Media Komputindo

A.S Rosa, M. Shalahuddin. 2013. Rekayasa Perangkat Lunak Terstuktur dan Berorientasi Objek. Bandung: Informatika

Bekti, Humaira' Bintu. 2015. Mahir membuat website dengan Dreamwaever CS6, CSS, dan Jquery. Yogyakarta : CV Andi Offset.

Kristanto, Andri. 2008. Perancangan Sistem Informasi dan aplikasinya. Jogjakarta : Gava Media

MADCOMS. 2016. Pemprograman PHP dan MySQ untuk Pemula. Yogyakarta: Andi

Sidik, Betha. 2017. Pemprograman web dengan PHP7. Bandung: Informatika

Sukamto, Rosa, Ariani, Muhammad Shalahudin. 2014. Rekayasa Perangkat Lunak Terstruktur dan Berorientasi Objek. Bandung : Informatika Bandung 